\title{
Cloning and sequencing of the light chain variable region from NS-1 myeloma
}

\author{
BOTAO NING, YONGMIN TANG, HUA SONG, SHILONG YANG and HONGQIANG SHEN \\ Department of Hematology and Oncology, The Children's Hospital, College of Medicine, \\ Zhejiang University, Hangzhou 310003, P.R. China
}

Received December 14, 2011; Accepted January 31, 2012

DOI: $10.3892 / \mathrm{ol} .2012 .601$

\begin{abstract}
The aim of this study was to clone the gene encoding the light chain variable region $\left(\mathrm{V}_{\mathrm{L}}\right)$ of the murine myeloma cell line P3/NS1/1-Ag4-1 (NS-1). Total RNA was prepared from the NS-1 cell line and its fusion hybridoma cell line $2 F 9$. The $V_{L}$ gene was amplified using reverse transcription PCR (RT-PCR) with family-specific primer pairs. The PCR products were cloned into the pGEM $^{\circledR}$-T easy vector, transfected into $E$. coli DH5 $\alpha$ cells and the positive recombinants were identified and purified with EcoRI digestion and agarose gel electrophoresis. The sequence was identified using an automatic DNA sequencer and analyzed online using the IMGT/V-QUEST program (version 3.2.21). The PCR product that was amplified with the P9 and P14 primers was approximately $392 \mathrm{bp}$ in size. Following digestion with EcoRI, the band of interest was also detected in positive recombinants using agarose gel electrophoresis. The sequences from the NS-1 and 2F9 cells were identical. The whole sequence was $387 \mathrm{bp}$ long, encoding 128 amino acids (AA), including a $60 \mathrm{bp}$ leader sequence. There was a TAA stop codon at 385-387 bp and only one cysteine was found, at 112AA/128AA. Analysis using IMGT/V-QUEST determined the cloned $\mathrm{V}$ - and $\mathrm{J}$-segments as murine $\mathrm{IG}_{\mathrm{K}} \mathrm{KV} 3$ $12 * 01$ and $\mathrm{IG}_{\mathrm{K}} \mathrm{KJ} 2 * 01$, respectively. Accordingly, the NS-1 $\mathrm{V}_{\mathrm{L}}$ gene belongs to the $\mathrm{Ig}_{\kappa}$ gene family V3 subgroup. The NS-1 $\mathrm{V}_{\mathrm{L}}$ gene was successfully cloned and it is a pseudo-Igк chain gene in NS-1 cells. This study may aid the sequencing of genes encoding monoclonal antibodies produced by mouse hybridomas raised with NS-1 myeloma.
\end{abstract}

\section{Introduction}

The P3/NS1/1-Ag4-1 (NS-1) cell line, which is derived from a BALB/c mouse with myeloma, synthesizes the $\kappa$ light chain

Correspondence to: Professor Yongmin Tang, Department of Hematology and Oncology, The Children's Hospital, College of Medicine, Zhejiang University, 57 Zhugan Lane, Yanan Road, Hangzhou 310003, P.R. China

E-mail: y_m_tang@zju.edu.cn

Key words: P3/NS1/1-Ag4-1 (NS-1), RT-PCR, sequencing, light chain but not the heavy chain and is a non-Ig-secreting subclone of P3X27 $(1,2)$. It was widely used in hybridoma technology for the production of monoclonal antibodies (McAbs) due to its high proliferation and cell-fusion rate (3). The property of synthesizing the $\kappa$ light chain of Immunoglobulin G (IgG1) with non-secretion causes certain problems in antibody engineering, for example the humanization of the murine-derived McAbs. To the best of our knowledge, there have been no studies performed concerning the sequence of the variable region gene of NS-1 cells. In this study, we synthesized 17 primers, 4 pairs of heavy chain primers and 9 light chain primers, to clone and sequence the genes encoding the variable region of the NS-1 cells using reverse transcription PCR (RT-PCR).

\section{Materials and methods}

Cell line, plasmids and main reagents. The NS-1 cell line was purchased from CellBank Australia (Wentworthville, Australia). The mouse hybridoma cell line ZCH-7-2F9 (2F9), which generated anti-human CD14 McAb, was established by our laboratory (4). E. coli DH5 $\alpha$, the restriction enzyme EcoRI, Taq DNA polymerase, M-MLV reverse transcriptase, RNasin ${ }^{\circledR}$, RQ1 RNase-free DNase, pGEM ${ }^{\circledR}$-T easy Vector system, X-gal, IPTG and TRIzol total RNA extract reagent were purchased from Invitrogen Life Technologies (Carlsbad, CA, USA). T4 DNA ligase, RPMI-1640 medium and fetal bovine serum were purchased from Gibco-BRL (Carlsbad, CA, USA) and the DL2000 marker was purchased from Takara Bio, Inc. (Shiga, Japan). The QIAquick Gel Extraction kit was purchased from Qiagen (Hilden, Germany). Olig(dT) $)_{12-18}$ primers were purchased from Promega (Mannheim, Germany).

Primer synthesis. The primers are cited by Chiang et al (5) and were synthesized by Sangon Biotech (Shanghai) Co,. Ltd. (Shanghai, China). The sequences of the primers are listed in Table I.

Cell culture. The NS-1 mouse myeloma and 2F9 mouse hybridoma cell lines were maintained in RPMI-1640 medium supplemented with antibiotics and $10 \%$ fetal bovine serum at $37^{\circ} \mathrm{C}, 5 \% \mathrm{CO}_{2}$ and saturated humidity.

Extraction of total RNA. For the isolation of total RNA from the NS-1 and 2F9 cells, TRIzol reagent was used according to 
Table I. DNA sequences of the primers used in reverse transcription PCR analysis.

\section{Primer number}

Primers for the variable region of the murine heavy chain

Forward primers complementary to the leading sequence

P1

$\mathrm{P} 2$

P3

P4

Reverse primers complementary to the J fragment

P5

P6

P7

P8

Primers for the variable region of the murine light chain

Forward primers complementary to the leading sequence

P9

P10

P11

$\mathrm{P} 12$

P13

Reverse primers complementary to the $\mathrm{C} \kappa$ and $\mathrm{J}$ fragment

P14

$\mathrm{P} 15$

P16

P17
Primer sequence $\left(5^{\prime}-3^{\prime}\right)$

atggaatgcagctgggtcatcctctt atgggatggagctgtgtaatgctctt atgaacttcgggetgagcttgatttt atggctgtcttggggetgctcttct

tgaggagacggtgaccatggtccc tgaggagactgtgagagtggtgcc tgcagagacagtgaccagactccc tgaggagacggtgactgaggtccc

atggagacagacacactcctgetat atggattttcaagtgcagattttcag atggagtcacagactcaggtctttata atggccccaactcagctcctggt atgaagttgcctgttaggctgttg

ccgttttatttccaacttggtccc ccgtttgatttcctgettggtgcc ccgtttcagctccagcttggtccc ggatacagttggtgcagcatcagcccgttt the manufacturer's instructions. Prior to reverse transcription, the total RNA was digested with RNase-free DNase and the quality was determined by agarose gel electrophoresis and ultraviolet spectrophotometer analysis. The cDNA coding for the variable chains was synthesized from the total RNA template using murine leukemia virus reverse transcriptase and Olig(dT) $)_{12-18}$ primers.

Cloning and sequencing. All DNA manipulation and bacterial transformations were based on the methods described by Sambrook et al (6). The conditions for PCR amplification were as follows: pre-denaturation at $94^{\circ} \mathrm{C}$ for $2 \mathrm{~min}, 30$ cycles of denaturation at $94^{\circ} \mathrm{C}$ for $30 \mathrm{sec}$, annealing at $57^{\circ} \mathrm{C}$ for $30 \mathrm{sec}$, extension at $72^{\circ} \mathrm{C}$ for $30 \mathrm{sec}$ and, following the final cycle, an additional extension at $72^{\circ} \mathrm{C}$ for $5 \mathrm{~min}$. The PCR products were purified according to the QIAquick DNA reagent kit instructions. The concentration was determined using an ultraviolet spectrophotometer. At a molar ratio of 3:1, the DNA fragment of interest and the $\mathrm{pGEM}^{\circledR}-\mathrm{T}$ easy vector were combined by $\mathrm{T} 4$ ligase in a $16^{\circ} \mathrm{C}$ water bath overnight. The product $(5 \mu \mathrm{l})$ was then transferred to competent DH5 $\alpha$ bacteria. Positive recombinants were selected on a Luria-Bertain (LB) plate with $\mathrm{X}$-gal, IPTG and $100 \mu \mathrm{g} / \mathrm{ml}$ Amp. The white bacterial colonies were amplified and plasmids were extracted and purified using the QIAquick DNA reagent kit. Following further determination with the EcoRI restriction enzyme and 1\% agarose gel electrophoresis, the DNA of the positive recombinants was sequenced.

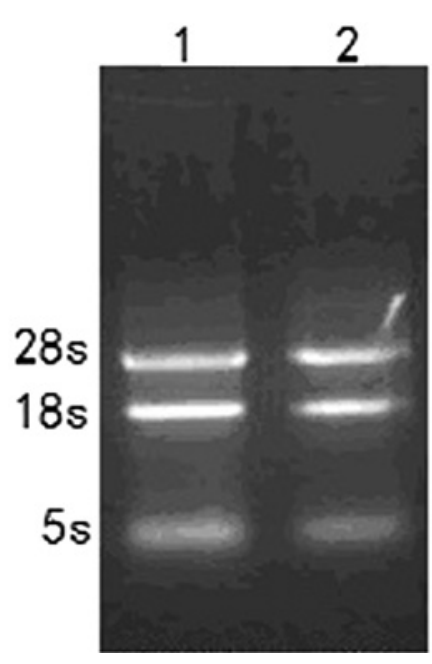

Figure 1. Agarose gel electrophoresis of total RNA from NS-1 and 2F9 cells. RNA preparations were electrophoresed in 1.5\% DEPC-treated agarose gel. Lane 1, NS-1 total RNA; lane 2, 2F9 total RNA. The gel was stained with ethylene dibromide. $28 \mathrm{~S}, 18 \mathrm{~S}$ and $5 \mathrm{~S}$ are ribosomal RNAs.

The genetic sequencing was performed using the dideoxynucleotide chain termination method with an automatic sequencer (ABI PRISM377). The sequence was determined using BLAST analysis (IMGT, the international ImMunoGeneTics information system ${ }^{\circledR}$ http://www.imgt.org). 
Table II. Detailed results of the IMGT/V-QUEST analysis of the NS-1 $\mathrm{V}_{\mathrm{L}}$ sequence.

\begin{tabular}{|c|c|c|c|}
\hline Segment of NS-1 $V_{L}$ & Gene and allele & Score $^{\mathrm{a}}$ & Identity, $\%^{\mathrm{b}}(\mathrm{nt})^{\mathrm{c}}$ \\
\hline $\mathrm{V}$ & Musmus $\mathrm{IG}_{\mathrm{\kappa}} \mathrm{V} 3-12 * 01 \mathrm{~F}$ & 1405 & $98.28(286 / 291)$ \\
\hline $\mathrm{J}$ & Musmus $\mathrm{IG}_{\kappa} \mathrm{J} 2 * 01 \mathrm{~F}$ & 171 & $97.22(35 / 36)$ \\
\hline
\end{tabular}

Result summary: unproductive IGк rearranged sequence (stop codons, out-of-frame junction). ${ }^{\mathrm{a} C a l c u l a t e d}$ by adding 5 for each nucleotide

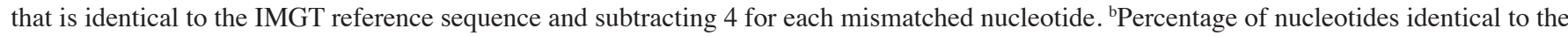
reference sequence. $V_{L}$, light chain variable region. ${ }^{c}$ Nucleotides identical to reference sequence/total number of nucleotides.
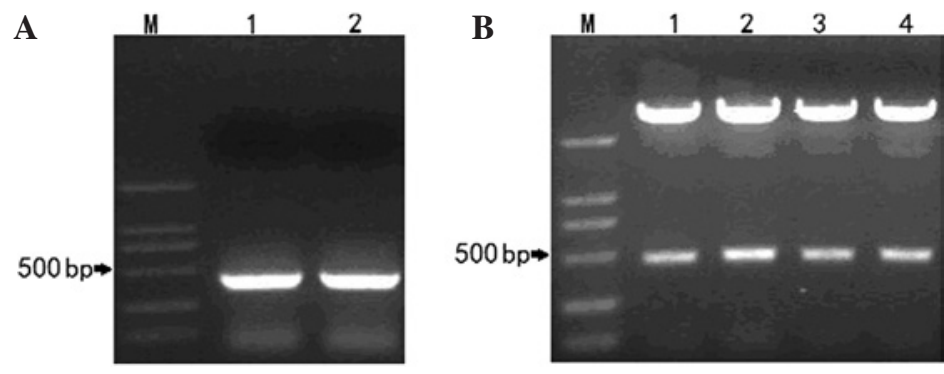

Figure 2. Electrophoresis of the PCR products and EcoRI-treated recombinant plasmids. (A) M, DL2000 marker; lane 1, template of NS-1; lane 2, template of 2F9. (B) M, DL2000 marker; lanes 1 and 2, recombinant plasmids from NS-1 cells; lanes 3 and 4, recombinant plasmids from 2F9 cells.

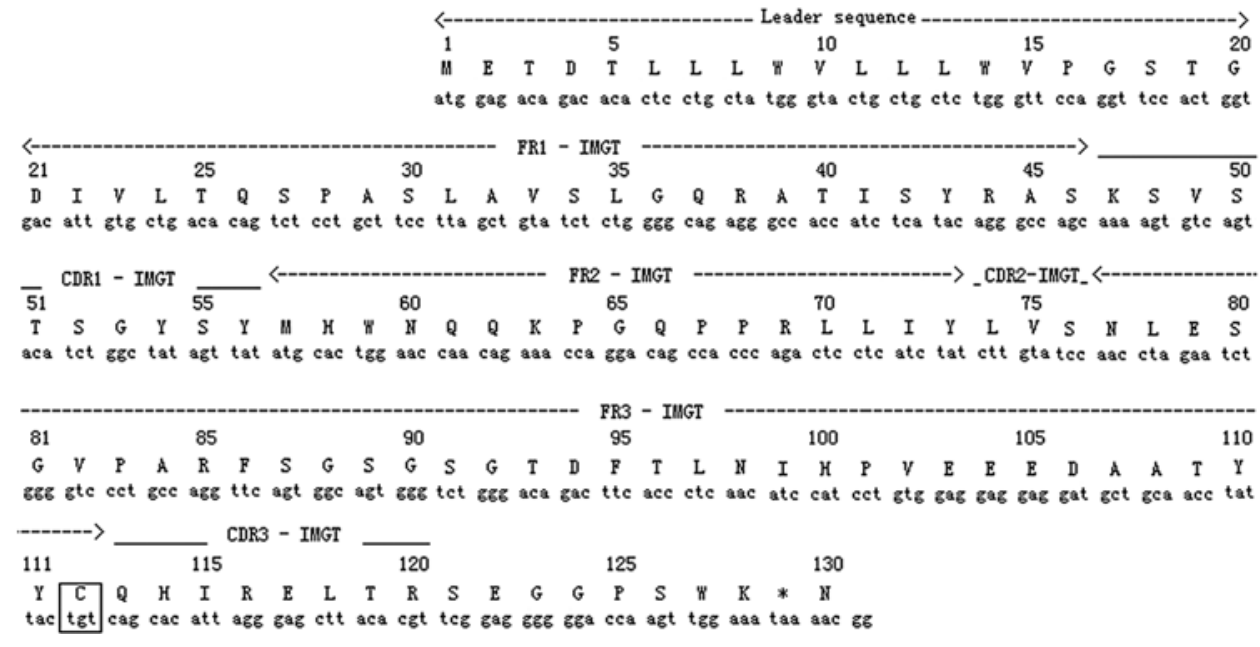

Figure 3. Nucleotide and deduced amino acid sequence of the NS-1 $\mathrm{V}_{\mathrm{L}}$. Leader, FR and CDR sequences are indicated by line arrows. The cysteine is shown in the box. $\mathrm{V}_{\mathrm{L}}$, light chain variable region; $\mathrm{FR}$, frame region; $\mathrm{CDR}$, complementarity determining region.

The study was approved by the Ethics Committee of The Children's Hospital of Zhejiang University School of Medicine.

\section{Results}

Extraction of total RNA. The total RNA was quantified using agarose gel electrophoresis. On the gel there were 3 clear bands of 28S, 18S and 5S ribosomal RNAs (Fig. 1). The A260/A280 ratio of the total RNA preparations was between 1.8 and 2.0. The yields of the total RNA were $\sim 40$ and $55 \mu \mathrm{g} / 10^{7}$ cells for NS-1 and 2F9, respectively.

Cloning and sequencing. Following PCR screening of the cDNA templates of the NS-1 and 2F9 cells, the light chain primers P9 and P14 amplified a specific band with a size of 392 bp in the NS-1 and 2F9 cells (Fig. 2A), whereas all the heavy chain primers were negative in the NS-1 cells. The positive recombinants contained the band of interest with a size of $\sim 400$ bp according to the results of the EcoRI digestion and agarose gel electrophoresis (Fig. 2B).

The results of the DNA sequencing revealed that the amplified light chain variable region $\left(\mathrm{V}_{\mathrm{L}}\right)$ from the NS-1 cells was identical to that of the $2 \mathrm{~F} 9$ cells. The nucleotide and deduced amino acid (AA) sequences of the NS-1 $\mathrm{V}_{\mathrm{L}}$ are shown in Fig. 3. The sequence was 387 bp long, encoded $128 \mathrm{AA}$ and included a leader sequence of $60 \mathrm{bp}$. There was a TAA stop codon at 385-387 bp and only one cysteine was found, at 112AA/128AA, as shown in the box in Fig. 3. The 
leader sequence, frame regions (FRs) and complementarity determining regions (CDRs) 1-3 of the $\mathrm{V}_{\mathrm{L}}$ were positioned as shown in Fig. 3. The gene segment family of the NS-1 $V_{L}$ was identified by a search for similarities against the IMGT/VQUEST database. The V-and J-segments were identified as Musmus $\mathrm{IG}_{\mathrm{k}} \mathrm{KV} 3-12 * 01$ and Musmus $\mathrm{IG}_{\mathrm{k}} \mathrm{KJ} 2 * 01$, respectively. Accordingly, the NS-1 $\mathrm{V}_{\mathrm{L}}$ gene belongs to the $\mathrm{Ig}_{\kappa}$ gene family V3 subgroup. The results were analyzed using the IMGT/V-QUEST program (version 3.2.21) and are summarized in Table II.

\section{Discussion}

When Köhler and Milstein first described hybridoma technology in 1975, it appeared to have the potential to develop treatments for a variety of human diseases (1). The technique involves forming hybridomas by fusing a specific antibody-producing $\mathrm{B}$ cell (from a murine spleen) with a murine myeloma cell (for example NS-1 or SP 2/0) that is selected for its ability to grow in tissue culture and for an absence of antibody chain secretion (8). The antibodies produced by the hybridoma are of a high specificity and are therefore McAbs. The fused hybridomas, being cancer cells, multiply rapidly and indefinitely and produce large amounts of the desired antibodies.

The uses of McAbs are numerous and include the prevention, diagnosis and treatment of disease, vaccine production and antigenic characterization of pathogens. However, in hybridoma technology the majority of McAbs are derived from mice and the clinical application of murine antibodies has been greatly restricted due to the occurrence of severe serum disease and the presence of human anti-mouse antibody (HAMA) in patients during therapy (9). Therefore, it is necessary to reduce the immunogenicity of the mouse antibody in order to be able to administer large doses of antibody repeatedly to patients. The most commonly used method is to humanize the murine-derived McAbs by gene cloning (10).

NS-1 and SP 2/0 are the two most widely used murine myeloma cell lines. Myeloma lines, including SP2/0 and X63.6.5.3, do not synthesize the heavy or light chains of immunoglobulins; therefore, hybridomas established with these myeloma lines secrete homogeneous McAbs with heavy and light chains derived only from spleen cells. However, myeloma lines such as NS-1 and P3U1 synthesize $\kappa$ light chains, although they are not secreted, meaning that the NS- $1 \mathrm{~V}_{\mathrm{L}}$ is encoded by mRNA $(11,12)$. This causes certain problems for the humanization of murine McAbs, including interrupting the sequencing of the $\mathrm{McAb}$ variable region genes. In this study, in order to resolve this problem, we successfully cloned and sequenced the NS-1 $\mathrm{V}_{\mathrm{L}}$ gene.

Following screening with 4 pairs of heavy chain primers by RT-PCR, no heavy chain variable region $\left(\mathrm{V}_{\mathrm{H}}\right)$ gene was observed; with 9 pairs of light chain primers, there was a 387-bp $\mathrm{V}_{\mathrm{L}}$ gene amplified with the $\mathrm{P} 9$ and $\mathrm{P} 14$ primers in the NS-1 and 2F9 cells (Fig. 2A). In order to avoid the influence of the residual genomic DNA, the total RNA was treated with RNase-free DNase prior to RT-PCR. Following the purification of the amplified NS-1 $\mathrm{V}_{\mathrm{L}}$ gene, we inserted it into the $\mathrm{pGEM}^{\circledR}$-T easy vector using TA cloning and the recombinants were checked with $E c o$ RI digestion and agarose gel electrophoresis. These steps ensured that the gene sequencing was reliable and accurate. The resulting sequence was identical in the NS-1 and 2F9 cells.

According to the analysis from IMGT (Table II and Fig. 3), the sequence contained 3 CDRs and 4 FRs, a TAA stop codon at the end of the cDNA and only one cysteine in the AA sequence. The NS-1 $\mathrm{V}_{\mathrm{L}}$ gene was a nonproductive IGK rearranged sequence and considered to be a pseudogene due to the stop codon and out-of-frame junction.

This study successfully cloned and sequenced the $\mathrm{V}_{\mathrm{L}}$ gene of the NS-1 cell line and determined that it was a pseudogene. The results of this study may prevent the selection of the wrong $\mathrm{V}_{\mathrm{L}}$ gene from the fused partner NS-1 cells during McAb humanization.

\section{Acknowledgements}

The study was supported by the National Natural Science Foundation of China (no. 30901327) and Zhejiang Provincial Natural Science Foundation of China (no. Y2100070).

\section{References}

1. Köhler G and Milstein C: Continuous cultures of fused cells secreting antibody of predefined specificity. Nature 256: 495-497, 1975.

2. Köhler G, Howe SC and Milstein C: Fusion between immunoglobulin-secreting and nonsecreting myeloma cell lines. Eur J Immunol 6: 292-295, 1976.

3. Tomita M and Tsumoto K: Hybridoma technologies for antibody production. Immunotherapy 3: 371-380 2011.

4. Tang YM, Ning BT, Cao J, et al: Construction and expression of single-chain antibody derived from a new clone of monoclonal antibody against human CD14 in CHO cells. Immunopharmacol Immunotoxicol 29: 375-386, 2007.

5. Chiang YL, Sheng-Dong R, Brow MA, et al: Direct cDNA cloning of the rearranged immunoglobulin variable region. Biotechniques 7: 360-366, 1989.

6. Sambrook J and Russell DW (eds): Molecular Cloning: A Laboratory Manual. 3rd edition. Cold Spring Harbor Laboratory Press, New York, 2001.

7. Siddiqui MZ: Monoclonal antibodies as diagnostics; an appraisal. Indian J Pharm Sci 72: 12-17, 2010.

8. Kennett RH: Hybridomas: a new dimension in biological analyses. In Vitro 17: 1036-1050, 1981.

9. Presta LG: Engineering of therapeutic antibodies to minimize immunogenicity and optimize function. Adv Drug Deliv Rev 58: 640-656, 2006.

10. Bernett MJ, Karki S, Moore GL, et al: Engineering fully human monoclonal antibodies from murine variable regions. J Mol Biol 396: 1474-1490, 2010.

11. Abe $\mathrm{N}$ and Inouye K: Purification of monoclonal antibodies with light-chain heterogeneity produced by mouse hybridomas raised with NS-1 myelomas: application of hydrophobic interaction high-performance liquid chromatography. J Biochem Biophys Methods 27: 215-227, 1993.

12. Cowan NJ, Secher DS and Milstein C: Intracellular immunoglobulin chain synthesis in non-secreting variants of a mouse myeloma: detection of inactive light-chain messenger RNA. J Mol Biol 90: 691-701, 1974. 